\title{
The Mechanism of “Big Data” Impact on Consumer Behavior
}

\section{Zilong Fang, Pengju Li}

College of Management, Shanghai University of Engineering Science, Shanghai, China.

Email: wwwfangyikuncn@126.com

Received November 22 ${ }^{\text {nd }}, 2013$; revised December 22 ${ }^{\text {nd }}, 2013$; accepted December $29^{\text {th }}, 2014$

Copyright (C) 2014 Fang Zilong, Li Pengju. This is an open access article distributed under the Creative Commons Attribution License, which permits unrestricted use, distribution, and reproduction in any medium, provided the original work is properly cited. In accordance of the Creative Commons Attribution License all Copyrights @ 2014 are reserved for SCIRP and the owner of the intellectual property Fang Zilong, Li Pengju. All Copyright (c) 2014 are guarded by law and by SCIRP as a guardian.

\section{ABSTRACT}

The growth of the network data is beyond the processing capacity of the existing IT infrastructure. At the same time, "big data" is also a major influence on consumer's behavior. C2C e-commerce consumption pattern is experiencing a vigorous development time of the electronic commerce in China. Because of its low threshold of setting up a shop which is occupying less money, low operating costs and obvious price advantages, low-income groups are welcome to this pattern. In case, this article analyzed the influence from five aspects: consumer behavior in security system, information search, recommendation system, credit system, virtual experience.

\section{KEYWORDS}

\section{C2C E-Commerce; Big Data; Consumer Behavior}

\section{Introduction}

With the coming of information age, each data type is developing at the speed of blowout. In the era of "big data”, "big data”, which is such a case, following the cloud computing and internet of things, becomes a new hotspot in the field of information. Modern enterprise use big data in e-commerce, especially C2C e-commerce. This reduces the asymmetric information and the trust risk in the virtual shopping experience, which affect consumers' shopping behavior patterns. Based on the analysis of the influence factors of big data for C2C e-commerce, we further analyze the mechanism of the big data's influence on consumer behavior. Through the analysis, the influence factors of large data on consumer behavior can help manufacturers adjust strategy to meet consumer demand.

\section{Big Data and Overview of C2C E-Commerce}

In the era of "big data", great changes of era have taken place. Huge amounts of data and the relevant technology of the big data has significant influence on the mode of C2C e-commerce. Therefore, understanding the big data and the definition and features of C2C e-commerce is vital for this study.

\subsection{The Definition and Characteristic of Big Data}

Wikipedia defines big data as "in a certain period of time, the data set could not be fetched the content, management by conventional software tools" [1]. Gartner which is an authority IT research and consulting firm defines big data as "in one or more dimensions, it is beyond extreme of traditional information management and the processing power of traditional information technology” [2]. The national science foundation (NSF) defines big data as "scientific instruments, sensors, Internet, E-mail, audio and video software, network click stream data sources generate a variety of large-scale, diversified, complicated and long-term distributed data set” [3].

In this paper, according to McKinsey and Merv Adrian's point of view, "big data” is that hardware and software can't in an acceptable time deal with data sets. The system has the following features. 1) Massive amounts of data (Volumes). An order of magnitude is rising continuously, from TB to PB, even EB [4]. 2) The 
mining potential. Vast amount of data contains a lot of valueless information [5]. 3) The diversity. There are large amounts of unstructured message data. 4) Information redundancy, huge amounts of data contains a great value, but which is filled with a lot of garbage information. 5) The speed of processing is fast. The emergence of a large number of advanced technologies greatly accelerates the data processing of technology [5]. 6) Risk is high. A large amount of data would inevitably involve the personal privacy. In addition, due to collection of a large amount of data, the growth of cost would be faster to make enterprise unprepared [4].

\subsection{The Definition and Characteristic of $\mathrm{C} 2 \mathrm{C}$ E-Commerce}

C2C e-commerce refers that the enterprises provide the network platform, not involve in trading, and consumers can free trade on the platform, and the seller can choose goods online auction, and the buyer can choose goods online bidding [6].

C2C e-commerce and traditional market have both similarities and differences.

1) Consumer characteristics: C2Ce-commerce contains various age groups of consumers, men and women, income inequality. Main is families and individuals. The amount of single transaction is not big. The most part of the sellers are individual. The size of the shop is not large. As they provide employment and the desire that people start cheap open a shop. So the quantity is huge [7].

2) The third party payment platform: The construction of third-party payment platform, through a third party credit instead of personal credit, solve the problem of both sides of the transaction security and trust, and reduce the perceived risk of both parties.

3) There is no space and time limitation: Traditional entity shop sales scale is limited by geographical environment. The network is a platform which can accommodate the various regions, nations and states of all kinds of goods. At the same time, the traditional store with a few exceptions, most of them are not open for 24 hours, but online consumers can choose their favorite goods anytime and anywhere [8].

4) More convenient choices: Consumers can never leave home, anytime and anywhere, using the search engines to query information about the goods. The customers just click the mouse to purchase goods [9].

\section{The Process of Decision-Making in C2C Mode}

The Engel, Blackwell and Miniard, they common put forward EBM consumer purchase decision model in 1990. The decision comes from demand recognition at first. When the consumers create psychological demand, they would gather information, selection, and evaluation, finally make a purchase decision [10]. Through analysis and weigh, consumers would make a buying decision.

According to BEM model, consumers need to experience the following several stages in decision-making (Figure 1).

1) Need recognition: When consumers aware the gap between the reality and the ideal state, and start to make purchase decisions, consumer demand confirmation has generated at this time.

2) Information search: After knowing your requirements, they would begin to search for relevant information. In the network environment, there are two main types of information channels [11]. The first is to show the commodity information. The second is the third party evaluation.

3) Evaluations of alternatives: The rational consumers would collect comprehensive information of goods. This process is very important in the buying decision. Compared with business information, consumers more concern objective evaluation of the third party.

4) Purchase decision: Network consumers' buying behavior depends on the following conditions. First, goods can meet the needs of the consumers. Second, the internet merchants must be worth trust. Third, online payment security is guaranteed [12]. The last is goods logistics is convenient.

5) Post-purchase behavior: Post-purchase behavior is a means that network consumers communicate each other. If consumers are satisfactory in the shopping experience, their evaluation is propaganda for the industry.

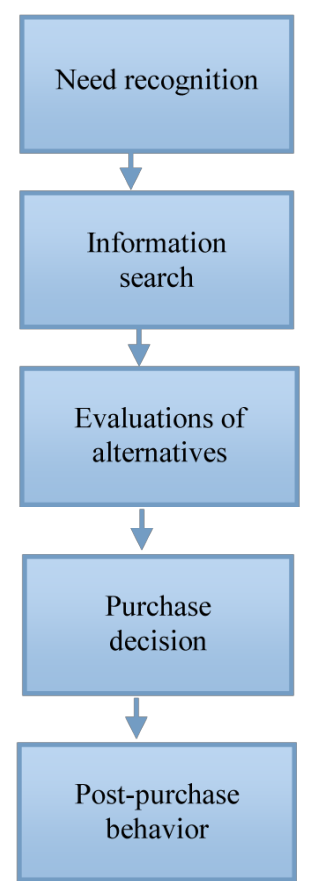

Figure 1. Purchase decision-making process of a consumer. 


\section{The Influence Mechanism of Big Data on Consumer Behavior}

Different from the traditional consumer behavior, in the era of big data, the accumulation of large data and technology of C2C e-commerce model bring new influence. As stated earlier, the consumer's purchase decision model has five stages. It is the same with shopping in traditional shopping environment. The advent of the era of "big data", the use of massive accumulation and technology is changing consumer behavior and feeling. We want to analyze the characteristics and influence factors of consumers' online shopping behavior, and then guide the online shopping behavior.

\subsection{The Influence of Security System on Consumer Behavior}

In $\mathrm{C} 2 \mathrm{C}$ e-commerce, online shopping is done in a virtual environment. And the information flow, cash flow, logistics is done in the separation of time and space. This provides the conditions of information camouflage for product suppliers, and increases the uncertainty of the network shopping and risky [13]. Most consumers worry illegal violation of personal information in the process of network shopping, which affect the online shopping behavior.

1) The influence of security system on information search

The development of modern information technology make the collection, analysis and use of personal information without permission become relatively easy. And there is the potential risk of personal privacy. Commodity information description is not clear because the understanding of goods on the network can only be done through pictures and text description. And some ambiguous description is easy to make people have different understanding.

2) The influence of security system on evaluations of alternatives

Different from the traditional way of shopping, online shopping, especially online payment, need consumers transmit information on the internet. The process of transmission is likely to be tampered by criminals unauthorized. Personal information or credit card information has been modified, copied, and deleted. This would increase the consumer perceived risk of online shopping.

3) The influence of security system on purchase decision

Due to network reduce the company resources that you enter and exit the market, the online store might disappear overnight. Compared with traditional shopping, returning goods on line shopping is a relatively trouble. Online retail goods depend on the impersonal electronic store to complete the transaction. And consumers cannot check goods entity. The product quality risk, returning and the cost of transportation would add the feeling of uncertainty.

4) The influence of security system on post-purchase behavior

In the network shopping, space and time block make the exchange of information between consumers and businesses should be done with the help of network. Goods delivery is typically implemented by third-party logistics companies. All this has weakened the consumerto monitoring efforts of the whole process of trading. Consumers cannot determine whether all sensitive information obtain the very good protection during transmission. These would make consumers full of sense of insecurity, especially the consumers who have had shopping security disputes lose trust.

\subsection{The Influence of Information Scanning on Consumer Behavior}

1) The influence of information scanning on need recognition

First, the emotional consumers are easy to induce their purchase desire and demand by network information. Second, as a rational consumer, rich product service information can better meet the needs of their rational judgment, and reduce the cost of information search [14].

2) The influence of information scanning on information search

Shopping on the Internet, consumers are often gathering information through online information. Consumers are swimming in the ocean of information. Of course, inevitably there is some false information. But overall, compared with traditional shop mode, the online shopping spends less time and effort. And the information is more comprehensive. It is helpful for consumers to buy cheap and fine commodity.

3) The influence of information scanning on evaluations of alternatives

The fully information is the basis of main decision. However a shopper's resources (including time, energy, and money) are limited. The quick and convenience of gathering online information is one of the main reasons for consumers. Compared with the traditional model, online consumption is not only a wide range selection but also can increase the perceived value of the network shopping.

4) The influence of information scanning on purchase decision

The intellect motivation is more than emotional factors. First of all; this is a process of thinking when consumers are looking for goods on the Internet. They have enough time and great convenience to analyze the price, quality, performance and appearance. Second; the network shopping is less affected by the outside factors, the physical 
and other buying behavior.

5) The influence of information scanning on postpurchase behavior

Consumers can search interest information. They filter and browse a large number of information. This can also be comprehensive use of this information. Consumers form their own judgment of products or service. This makes the initiative of online trading in the hands of consumers.

\subsection{Recommendation System's Influence on Consumer Behavior}

Recommendation system is based on the customer's purchase behavior, browsing behavior. Recommendation system can evaluate commodity information, learn interest of the customers, products matching, recommend customers to similar goods [15].

1) The influence of recommendation system on need recognition

Studies have shown that consumers can't form a stable and clear preference as they lack complete and accurate grasp of product information. Consumer's choice preference is not fixed, but correcting as the change of information in the process of buying. Therefore, recommendation system brings the consumers comprehensive, fully and personalized information. This changes consumer preferences. The result of the survey also shows that consumers are effected by website information and promotional when consumer is choosing goods. They think that recommendation is to give them more reference and bring more inspiration [16].

2) The influence of recommendation system on information search

Information search is the best ability of recommendation system. Recommendation provides consumers with more comprehensive and more fully, more personalized information. This makes the consumers have the deeper and more accurate evaluation about product function, performance and price and so on, so as to reduce the cognitive deviation of different brand products.

3) The influence of recommendation system on evaluations of alternatives

Recommend system often provide consumers information such as expert reviews and customer reviews at the same time. These would affect consumer product evaluation and attitude on different extent. In buying decision process, recommendation system would affect consumer preference function, the product evaluation and selection strategy. Preference function change means the change of standard of consumer choice. This would cause the search range of products, product evaluation criterion and product consideration set and a series of changes. Product evaluation change means the change of consumer attitudes and purchase intention of corresponding products. Product screening strategy change means that consumers would use different way of thinking, method and path to select products. Obviously these would bring the final different choice.

4) The influence of recommendation system on postpurchase behavior

Recommendation system can save consumers a lot of time of information search, evaluation and selection; provide consumers with more comprehensive and quick information. Recommendation system expands the scope of product search and the evaluation; make consumers have greater product selection, thereby enhance the level of consumer purchase decision. These increase consumer trust and confidence on emotion.

\subsection{Credibility Impact on Consumer Behavior}

1) Credibility's influence on evaluations of alternatives

Credibility is acquired in the previous experience and interaction with others. The information is asymmetry between the seller and the buyer. Consumer cannot discern the stand or fall of product. There is the problem of adverse selection. Credit can improve the condition of the information asymmetry [17]. The buyers think the seller would provide the high quality service, when consumer is choosing high credit rating and the better goods.

2) Credibility's influence on purchase decision

The biggest characteristic of online shopping is price advantage compared with traditional shopping way. "Big data" technologies make information transfer at a relatively low cost operation. It has the significant advantages to build credibility. In addition, when the reputation is high, the impact of price and buying behavior is very weak.

When business reputation is the high, users would be fewer prices sensitive. At this time, merchants can set up a relatively high price in order to get more profit. On the other hand, for the merchants of low credibility, they should be set a low price to earnings. The conclusion has a high reference value for price strategy. Consumers tend to choose the merchants of high credit rating and better network evaluation.

3) Credibility's influence on post-purchase behavior

The speed and breadth of information transmission can't be measured in cyberspace. Consumers would reflect the good experience in online after purchase [18]. Consumers would not only repeat purchase, but also positively recommend the goods to others. These may be benefit to the manufacturer. But if consumers are not satisfaction after shopping, they are likely to express it through the network, so that the vast number of internet users has a harmful effect on the heart, and many potential consumers lose purchase desire. The evaluation of virtual community and businesses credit rating would 
affect consumers' trust.

\subsection{Virtual Experience's Influence on Consumer Behavior}

In the environment of virtual experience, consumers are no longer satisfied with the function of the products, but more concerns about the emotional appeal of products, namely products bring the experience of consumers.

1) The influence of virtual experience on need recognition

In the process of consumption, consumers not only pay attention to the quality of the product, but also pay more attention to the feelings of pleasure and satisfaction [19]. The consumers' pursuit products and services can contribute to the personalized image formation and reveal their uniqueness [20]. The purpose that consumers purchase goods is an emotional desire, prefer those who can resonance between perceptual product and self psychological needs [21].

In the virtual shopping experience, the more the image perceptual experience, more direct individualized experience, the independent factors of the active participation would stimulate the desire of the product buyers.

2) The influence of virtual experience on information search

In today's highly developed Internet, consumers don't fret the lack of information, but information too much, too miscellaneous, so that they can't choose. In the virtual experience of C2C e-commerce, beautifully designed website, the style and atmosphere which conforms consumer preferences can stimulate the consumers' emotional reaction [22]. Consumers often experience various brands of products in order to obtain the most direct information. That they need.

3) The influence of virtual experience on evaluations of alternatives

Compared with the traditional marketing environment, in the virtual experience, consumers no longer believe too much the evaluation information of alternative products that business advertise. They are increasingly used to search information in virtual community of the assessment, or rely on their own experience of products.

4) The influence of virtual experience on purchase decision

The interaction mechanism of the site solves customers' questions in a timely manner to attract more and more consumers and discussion and sharing of product information in consumption experience. Generated by expansion of information capacity platform and an increasing number of people network effects can effectively reduce the insecurity of consumers' online purchase and build confidence in the trading process. Consumer's decision-making behavior in virtual experience is the initiative.
5) The influence of virtual experience on post-purchase behavior

The buying process is also the experience of product process. Unlike post-purchase evaluation, the post-purchase evaluation of virtual experience would not be decided by the features of the product, but consumption experience. Purchases in any detail can produce very big effect on post-purchase evaluation [23].

\section{Conclusion}

The emergence of the big data is a new challenge to information security. If consumers do not understand the big data, they would have a new worry. The convenience and quick information search let consumers rely more on big data. Recommended Network provides more choices for consumers. They are more likely to believe postpurchase evaluation and other consumers. Consumers have been tired of the advertising campaign. They are more likely to experience marketing, pursuit the personal experience and participate in marketing.

\section{REFERENCES}

[1] Big Data. http://en.wikipedia.org/wiki/Big_data .

[2] Big Data. http://www.gartner.com/it-glossary/big-data

[3] Core Techniques and Technologies for Advancing Big Data Science \& Engineering (BIGDATA) http://www.nsf.gov/funding/pgm_summ.jsp?pims_id=504 767 .

[4] L. Sun, "When Talking about Big Data, What Do We Talk about,” Business Technology, Vol. 350, 2012.

[5] W. Feng, "Opportunity and Challenge of Information Security Faced by the Era of Big Data," Expert Views, 2013.

[6] X. Y. Zhang, "The Existing Problems and Solutions in the Development of C2C E-Commerce in Our Country," Information Method, No. 6, 2005.

[7] R. H. Zheng, "C2C E-Commerce Logistics Distribution Study,” Logistic Theory, 2011.

[8] J. M. Huang, "Discuss the Potential Development of China's C2C E-Commerce Model," Economic and Trade BBS, 2010.

[9] R. Zhou, "Introduction to China's C2C E-Commerce Market Present Situation and Development Trend,” Modern Economy, No. 7, 2011.

[10] L. L. Zhang, "Enlightenment of EBM Model to Network Marketing,” Business Modernization, Vol. 386, 2009.

[11] M. L. Liu, "For Electronic Commerce: An Empirical Study of Factors Affecting Consumer Behavior," Network Economy and E-Commerce, No. 7, 2006.

[12] H. Chen, "In the Condition of Electronic Commerce, the Factors Analysis of Consumer Purchase Decision," Beijing University of Posts and Telecommunications, No. 2, 2007.

[13] X. Q. Wen, “The Consumer Behavior Research of Net- 
work Shopping,” Journal of Lanzhou, Vol. 189, 2006.

[14] C. Y. Hong, "The Influence of Internet Information Search Intention on Consumer Behavior Analysis," Foreign Economic and Trade University, No. 6, 2013.

[15] S. X. Wang, "Recommendation Scheme Based on Shopping Orientation Research,” Journal of Integration Technology, No. 3, 2013.

[16] D. Zhao, "Recommendation Model Based on Network Shopping Review," Southwest University for Nationalities, No. 3, 2012.

[17] X. F. Zhang, "The Value of Credit: The Explaining of the Characteristics of Electronic Market in China Based on Data of Taobao,” Contemporary Economic Science, No. 3, 2009.
[18] C. B. Li, "The Role of Reputation System in Online Trading," Credit/The Rule of Law, No. 4, 2013.

[19] W. H. Su, "Web Experience Marketing and the Way of Study,” Business Management, No. 10, 2009.

[20] S. Y. Pei, "Network Consumer Behavior Research, Review and Evaluation,” Marketing Online, No. 4, 2010.

[21] Y. F. Cao, "Network Consumer Behavior Research Review,” Marketing Research, Vol. 477, 2006.

[22] A. Z. He, "Online Shopping Experience on Customer Behavior Mechanism and Model,” East China Economic Management, No. 3, 2010.

[23] X. M. Mao, “The Research of Experience Marketing of Consumer Behavior,” Marketing Tribune, No. 2, 2009. 